\title{
INTRODUCTION TO TECHNOLOGICAL EDUCATION STUDENTS WITH THE TYPES OF NATIONAL ORNAMENTS AND TEACHING THEM TO IMPLEMENT
}

\author{
${ }^{1}$ Ruziev E.I., ${ }^{2}$ Tajiev J.K., ${ }^{3}$ Ruzmetov K.Sh. \\ ${ }^{1}$ Doctor of Pedagogical Sciences, Professor of Urgench State University, Urgench, Uzbekistan. \\ ${ }^{2}$ Basic doctoral (PhD) student of Urgench State University, Urgench, Uzbekistan. \\ ${ }^{3}$ Senior Lecturer, Department of Fine Arts and Engineering Graphics, Urgench State University, Urgench, Uzbekistan.
}

\begin{abstract}
Patterns have a special place in many areas of Islamic culture, such as folk crafts, applied arts, architecture. Uzbek national patterns differ from the patterns of other nations by their elegance, perfection and originality. The article discusses examples of introducing future technology education teachers to the types of national patterns and teaching them to perform them.
\end{abstract}

Keywords:

folk handicrafts, applied arts, patterns, painting, girikh, islimi

Article Received: 18 October 2020, Revised: 3 November 2020, Accepted: 24 December 2020

\section{Introduction}

Development of national handicrafts, folk arts and crafts in the Republic of Uzbekistan, thereby preserving the rich cultural heritage and historical traditions of the people, attracting the unemployed, especially youth, women and lowincome families to mass forms of handicrafts and applied arts. Much attention is paid to practical work on ensuring These changes are also reflected in the education system of the country in improving the training of personnel in the field of national crafts and applied arts. In particular, the system of training in vocational education in the field of national crafts and applied arts is being improved, the content of training of teachers of "Technology" for secondary schools and vocational education institutions in higher education institutions is being revised in accordance with modern requirements. In addition to the competencies that students should acquire in the "Technology" classes in secondary schools, the teacher of technology is expected to acquaint them with the basics of folk arts and crafts and the formation of skills to make simple products. In the bachelor's degree in "Technological Education" these skills are formed in the discipline "Folk Crafts and Artistic Design." The subject "Folk
Crafts and Art Design" is aimed at developing the professional competencies of future technology teachers.

\section{Materials and Methods}

Patterns are common in Central Asia, and they are mainly divided into two types: the most complex type of pattern, consisting of geometric shapes and lines - girih, the most common plantlike pattern - islimi (Figure 1). Painting developed under the influence of each region's unique environment: geographical location, people's customs, religious beliefs, and the country's flora. For example, in Armenians and Georgians grapes and grape leaves, in northern peoples flowers, peppers and others were used as symbolic patterns. The types of patterns in Muslim nations are mainly in the Girih and Islimi types, in which geometric patterns and plant motifs predominate without depicting living beings. Painting schools such as Bukhara, Khorezm, Tashkent and Fergana have been formed in Uzbekistan. The patterns in them differ in shape and the application of colors.

Different patterns of the peoples of the world, the history of their development have been studied by researchers such as Butkevich L.M., Chernikhov Ya.G., Fokina L.V. Textbooks and manuals on national patterns and their teaching to 
students have not been published in Uzbekistan so far. Therefore, in higher education institutions trained by technology education teachers, much attention is paid to teaching students the types of crafts that are popular in the local area. The department of "Technological Education" of Urgench State University has accumulated unique experience in the formation of competencies of future teachers of technology in Uzbek folk crafts and applied arts.

Members of the department in collaboration with the Department of Fine Arts and Engineering Graphics of the University collected sketches of pattern compositions created by representatives of the Khorezm School of Painting, which are still little studied (Figure

$1)$.
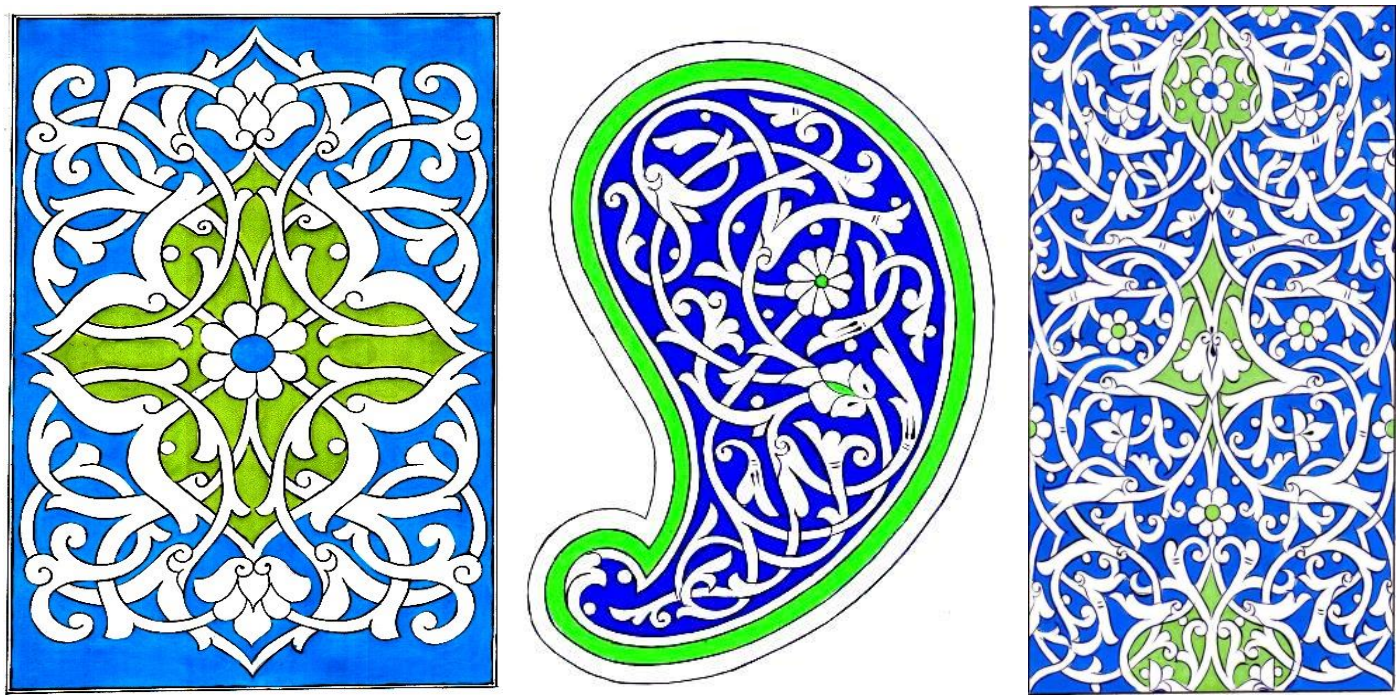

Figure 1. Samples of restored patterns on the sketches of Kamil Devoni, a representative of the

Khorezm School of Painting (variants restored by K. Ruzmetov and Sh. Kalandarov)

Khorezmian patterns, especially Islamic patterns, differ greatly from the patterns of other regions of Uzbekistan in their graphic shape and colors. These patterns are mostly done on a blue background and have an intricate look. The most perfect examples of Islamic patterns are well preserved in the historical monuments of Khiva to the present day (Figure 2). Even today, the tradition of decorating gifts, household items, etc., made by local craftsmen with national patterns has been preserved (Figure 3). That is why the art of painting is an important component of national crafts.

Figure1. Samples of restored patterns on the sketches of Kamil Devoni, a representative of the Khorezm School of Painting.

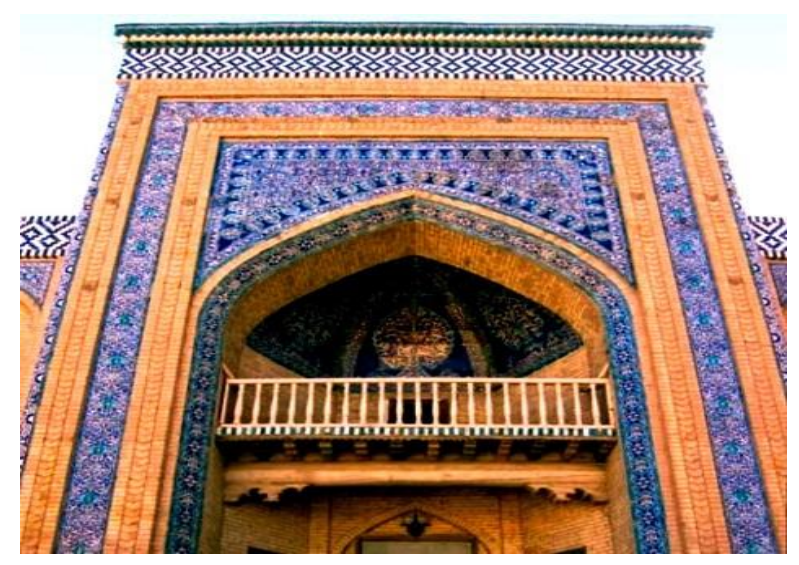

a)

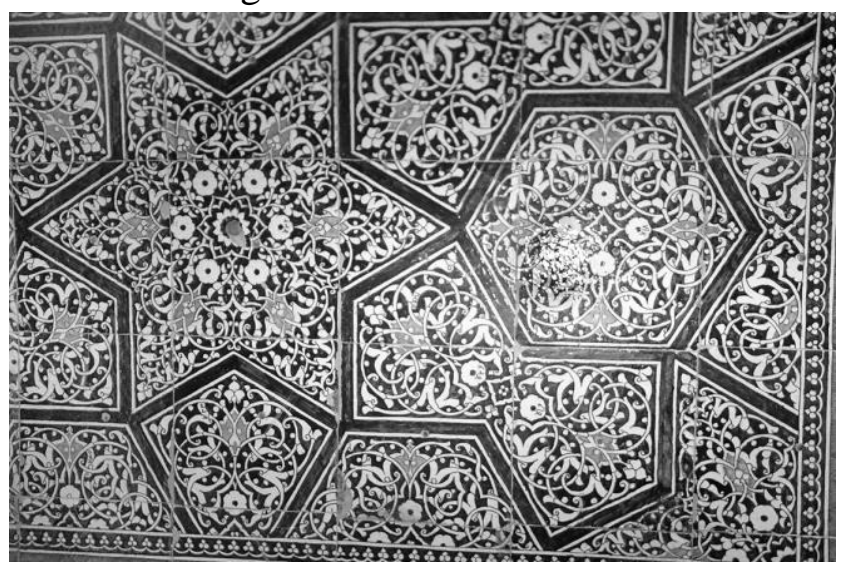

b) 
Figure 2. a) Application of national patterns on the portal of Islamkhoja madrasah in Khiva; b) a composition of national gyrich and islimi patterns on glazed pottery of historical monuments (Khiva)

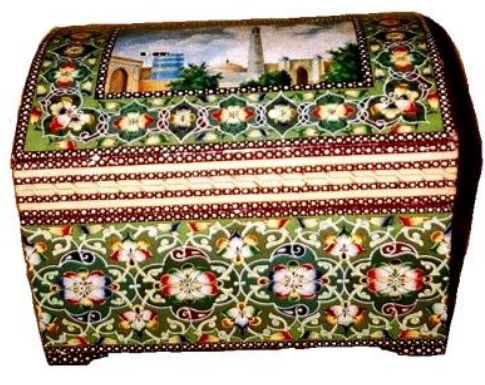

a

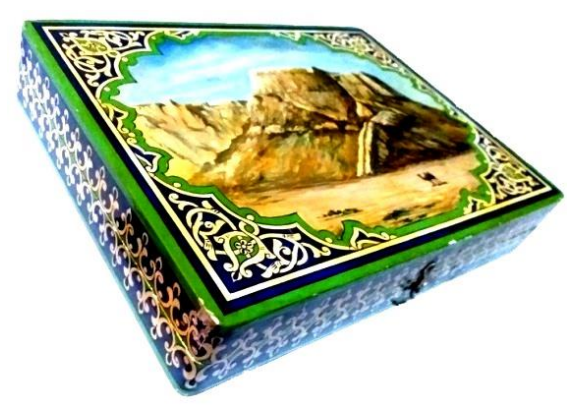

b

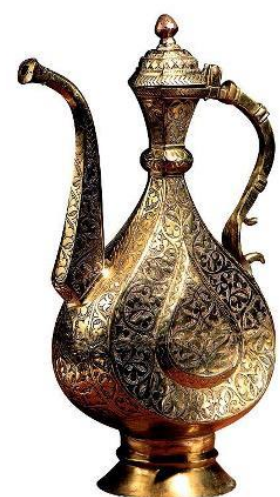

c

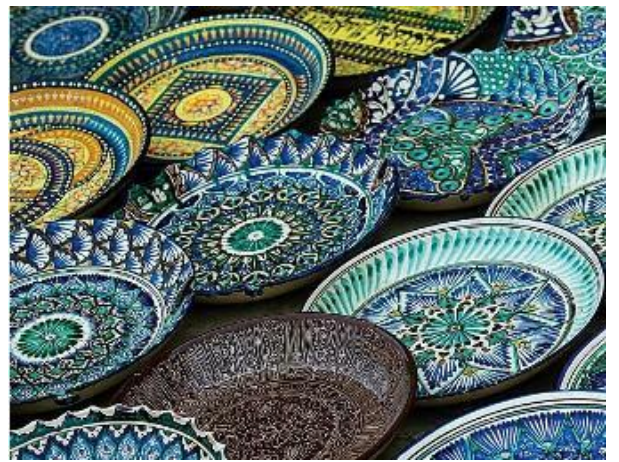

d

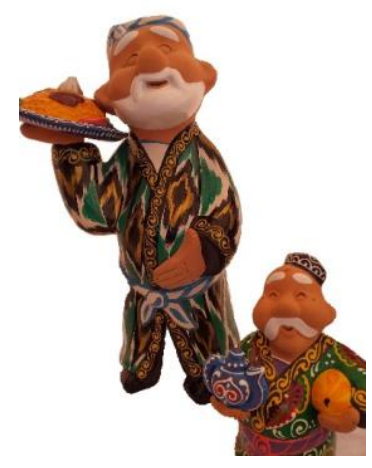

e

Figure 3. Decoration of gifts and everyday items in the national style: a) box;

b) box (student creative work, supervisor: K. Ruzmetov, 2014); c) sand; d) bowls; e) ceramic figurines

Patterns play an important role in Uzbek folk arts and crafts due to their beauty and elegance, they are widely used in the decoration and manufacture of architectural monuments, household items and gifts (Figures 2, 3, 4). In the process of forming students' competencies in folk crafts and applied arts, it is important, first of all, to form knowledge and skills on the elements of national patterns and the creation of pattern

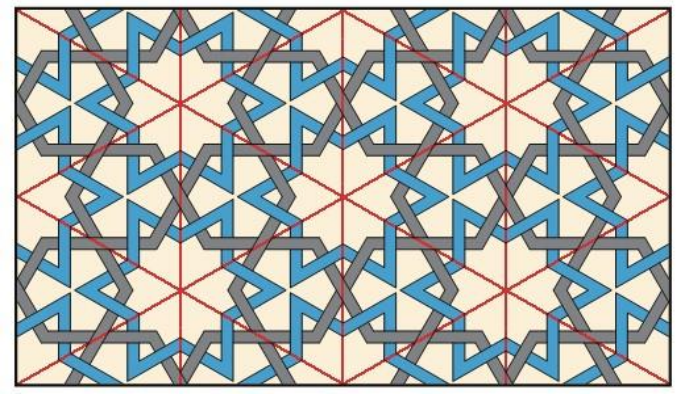

a compositions based on them. Therefore, teachers working in higher education institutions, which train specialists in applied arts and folk crafts, are required to have a sufficiently thorough mastery of the skills and abilities of pattern making. The teacher should have the skills to select pattern compositions appropriate to the items, and to create new pattern compositions that are less complex if necessary.

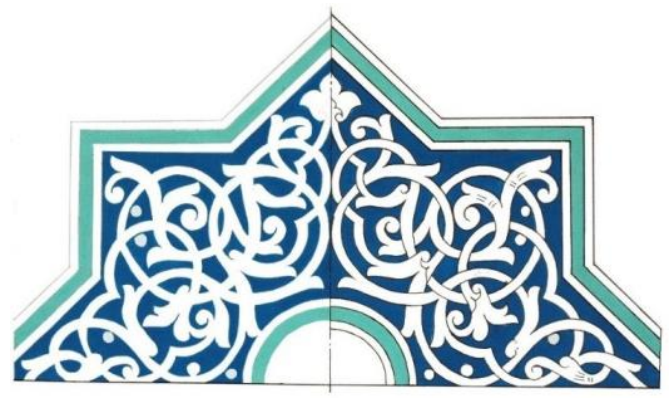

b 


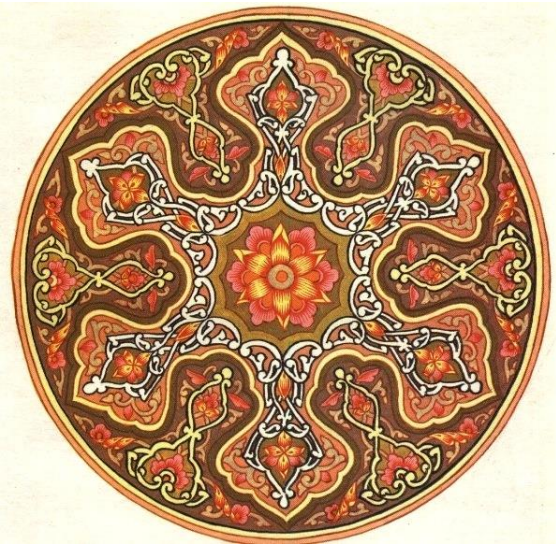

C

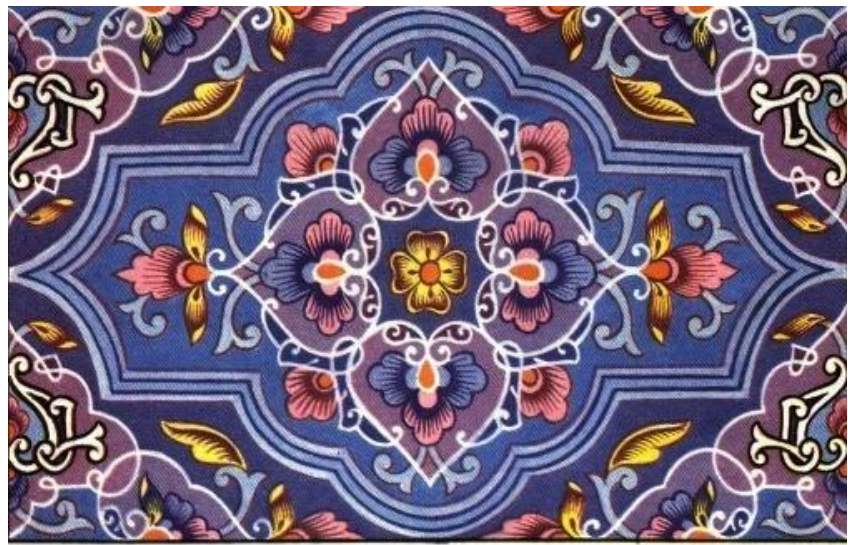

d

Figure 4. Examples of national patterns of Uzbekistan: a) - entrance pattern; b) - floral entrance pattern; c), d) - islimi patterns.

At present, due to the fact that textbooks and manuals on the subject "Folk Crafts and Art Design" for the direction of "Technology Education" have not been published, K. Abdullaeva et al. "Artistic processing of fabrics", "Applied art" by K.Gulamov, "Folk handicrafts" by M.Maksimova and K.Abdullaeva are used. Due to the brief coverage of the composition and execution of national pattern compositions in these manuals, it is difficult for students to master the skills of pattern making at the required level. Many professors in this subject try to explain this by the low level of students' basic knowledge of graphics, especially fine arts. S.Bulatov's manual "Uzbek folk applied decorative art" (T .: 1991) can be used effectively in the development of students' competencies in pattern making, but although this manual describes in detail the stages of composing national pattern compositions, there are few materials on creating new compositions independently.

Taking into account the above, the Department of "Technological Education" of Urgench State University pays special attention to teaching students to perform "author's patterns" independently, along with the performance of national patterns in the educational process on the subject "Folk Crafts and Art Design". Most students in the field of technology education face difficulties in making graphic images and painting them with colors. It is advisable for students to start with national patterns - geometric patterns. Because most students in the field of technology do not have well-formed visual activity skills, they find it difficult to perform hand-made patterns. National geometric patterns - the entrances are made mainly with the help of drawing tools, and when the shape is ready, the throne is treated with color.

Girix is a type of Arabic pattern that has no analogues in world art [4, 152]. Entries can be seen as a shining expression of the harmony of art and mathematics. These patterns are constructed from modular polygons that propagate along radial symmetry. They are built using precise measuring instruments and are based on specific mathematical calculations. National monuments of historical monuments and settlements in the territory of modern Uzbekistan, including the structure of the entrances and the laws of their construction L.I. Rempel [14]. It has been studied by a number of local researchers such as M.S. Bulatov [2], G.A. Pugachenkova [13], S.S. Bulatov [3], Q. Kasimov [11], J. Bonner in his "Islamic Geometric Patterns. Their Historical Development and Traditional Methods of Construction" [1] provides a detailed analysis of the history of the development of geometric patterns, one of the brightest examples of Islamic culture. The manual shows how to build entries from simple to complex using geometric constructions. 
Girix is a Persian word meaning "problem", "knot", "mess", and is widely used in architecture and artistic craftsmanship. Entrances are mainly built in "nets" that form knots. All constructions in the construction of the entrance begin with the determination of the basic shape of the "net" and its location. Sometimes a single patterned net is placed on top of a second pattern net to form a complex shape. The basis of Girix construction often lies in the method of dividing the circle into equal parts and thereby forming squares, rectangles and polygons. In general, entrances are constructed using a compass and ruler. Dozens of competing geometric patterns can be placed side by side in a Girix composition. Such compositions are formed by methods such as placing polygons on a polygon, polygons on a circle many times.

Any input is built on the basis of precise mathematical calculations, based on rational series, and as a result it is possible to create an
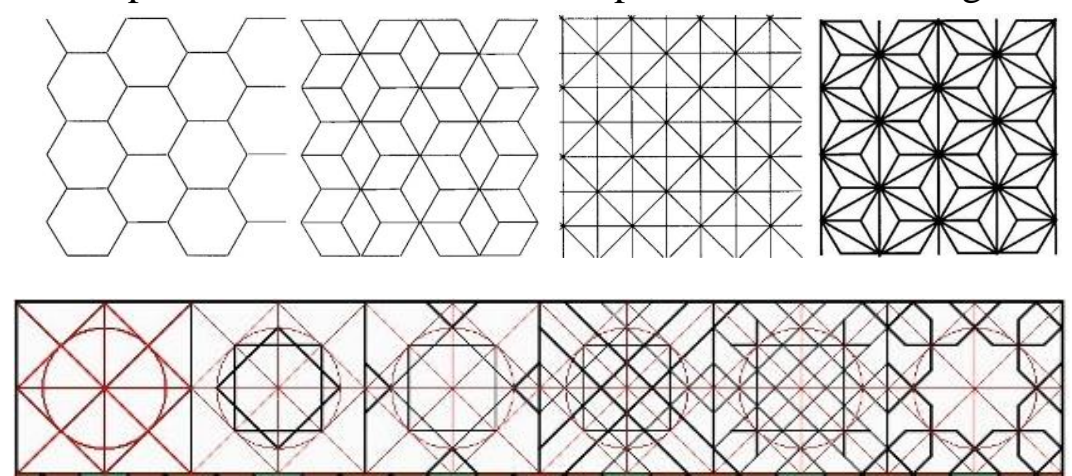

Figure 5. Recommended "nets" to use in the construction of the girth composition and a simple method of gyrich construction.

Students' creative abilities can also be developed by performing gyrich patterns in the form of "rosettes". The department has developed a method of making orange patterns using a compass and developed a number of options for this task (Figure 6). Once students have taken the infinite number of variants of input. The success of the East, including the art of Uzbek painting, is directly related to the great discoveries in the field of mathematics.

It was found that the entries were made with the help of drawing tools - a ruler and a compass, and it was not difficult to master these skills, so the students performed the new entries with high quality and with great interest.

The simplest methods of composition were suggested when creating a task variant on Girix. Simple geometric shapes - squares, rectangles and hexagons - were taken as the basis (initial grids), in which explanations were given on the performance of geometric patterns (Figure 5). After that, the students prepared a composition based on "their own options" and prepared to submit the work. The content of this task can be offered in the form of "sketch of the entrance pattern" on something - a box, a chair.
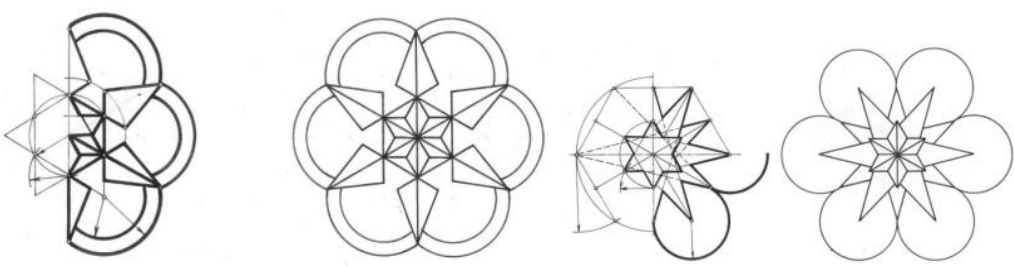

Figure 6. Options for a simple execution of the pattern "orange" with the help of a compass and ruler (options prepared by Professor E. Ruziev) 
Results

After introducing the students to the rules of composition and composition of folk songs in the classes of folk arts, the students began to perform the tasks with great interest. In the graphic assignments on the entries, taking into account the individual interests and abilities of the students, they were asked to complete a generalized assignment instead of several smaller assignments. As these assignments, the student was asked to prepare "gifts" or "visual aids" that could be used in the learning process. as a result, some students also suggested creative "authorship" solutions (Figure 7-8).
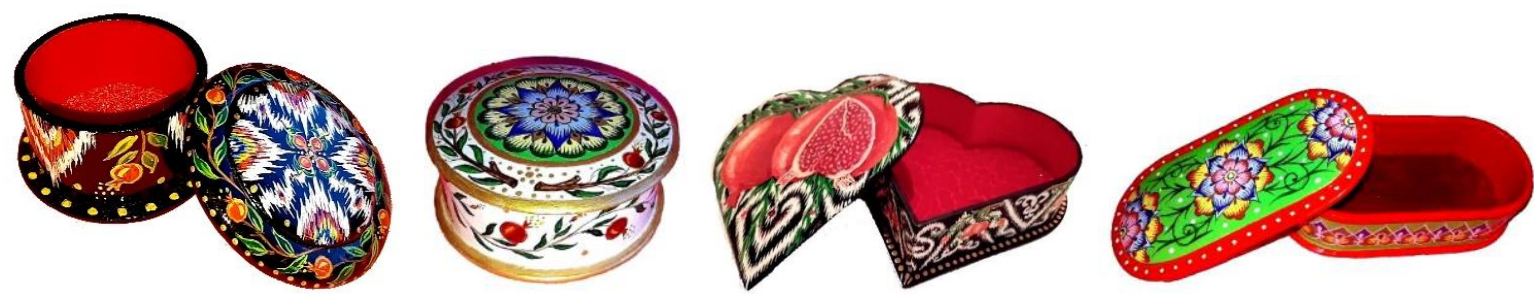

Figure 7. Boxes. (Gifts made by student Shonazarova Matluba, 2018)

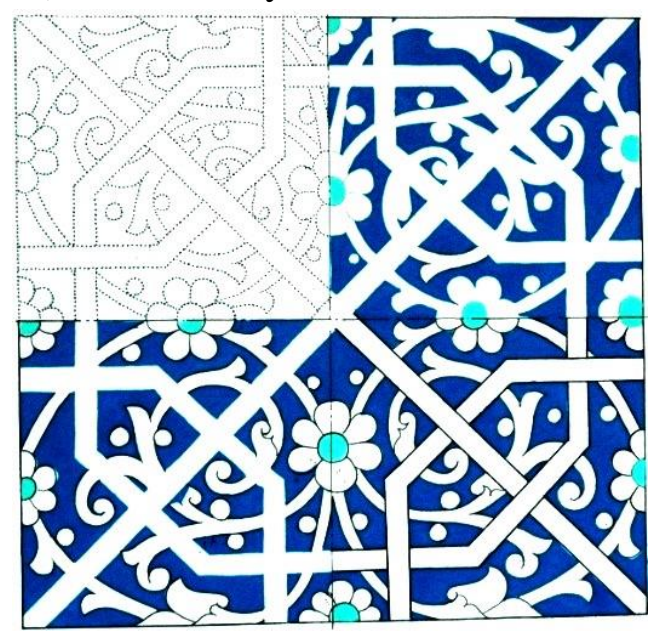

Figure 8. Stages of making a flower entrance composition

\section{CONCLUSIONS, ACKNOWLEDGEMENTS}

The organization of classes to teach students to perform national patterns in this order increases their interest in science and develops their ability to independently research and create. The products of folk handicrafts and applied arts made by students of the "Technological Education" direction of the University are presented and awarded at regional and national exhibitions and competitions.

\section{References}

[1] Bonner J., Islamic Geometric Patterns, Springer-Verlag New York, 2017.

[2] Bulatov M.S. Geometricheskaya garmonizatsiya v arhitekture Sredney Azii IX-XV vv. - M .: Nauka, 1988. -
$363 \mathrm{p}$.

[3] Bulatov S.S. Uzbek folk applied decorative art. - T .: Mehnat, 1991. - 321 p.

[4] Bulatov S.S., Gulomova N. Geometric bases of pattern making. - $\mathrm{T}$.: TDPU, 2004. - 53 p.

[5] Bulatov S.S. Painting. $T$. «ECONOMY-FINANCE», 2010, -368 p.

[6] Butkevich L.M. History ornament .: ucheb. posobie dlya stud. vyssh. ped. ucheb. zavedeniy. $\mathrm{M}$.: Humanitarian. izd. center VLADOS, 2008. - 267 s, 8 s. il.

[7] Chernixov Ya.G. Ornament. Kompozitsionno-klassicheskie 
postroeniya. M., «Svarog i K», 2007. $200 \mathrm{p}$.

[8] Crafts and applied arts of Uzbekistan. Encyclopedia. Volume $1 \mathrm{~T}$ :. "National Encyclopedia of Uzbekistan" State Scientific Publishing House, 2016. - 496 p.

[9] Crafts and applied arts of Uzbekistan. Encyclopedia. Volume $2 \mathrm{~T}$ : "National Encyclopedia of Uzbekistan" State Scientific Publishing House, 2017. -432 p.

[10]Fokina L.V. History of decorativeapplied art. Rostov n / D: Phoenix, 2009. $-239 \mathrm{p}$.

[11] Kasimov Q., Painting. - T .: Teacher, 1990. - 160 p.

[12] Khudayberganov A.N., Tojiev J.K. Formation of artistic design skills of technology teachers (Monograph), $\mathrm{T}$.: 2019. - 138 pages.

[13] Pugachenkova G.A, Rempel L.I., Art history of Uzbekistan, M.: "Iskusstvo", 1965. $-688 \mathrm{p}$

[14] Rempel L.I. Architectural ornament of Uzbekistan. Istoriya razvitiya i teoriya postroeniya.Tashkent, Gosudarstvennoe izdatelstvo xudojestvennoy literatury UzSSR, 1961. - $605 \mathrm{~s}$.

[15]Ruziev E.I., Tojiev J.K. Folk Crafts and Art Design (Practical training on "Folk Crafts and Applied Arts"), T .: 2019. $5.5 \mathrm{pp}$.

[16] 16. Ruziev E.I. Grometric and projection drawing. - T .: Yangi asr avlodi, 2010. 309 p. 